\title{
Left Atrial Enlargement in Young High-Level Endurance Athletes - Another Sign of Athlete's Heart?
}

\author{
by \\ Wojciech Król' ${ }^{1}$, Ilona Jędrzejewska ${ }^{1}$, Marcin Konopka ${ }^{1}$, \\ Krystyna Burkhard-Jagodzińska², Andrzej Klusiewicz², Andrzej Pokrywka², \\ Jolanta Chwalbińska ${ }^{3}$, Dariusz Sitkowski², Mirosław Dłużniewski, \\ Artur Mamcarz ${ }^{4}$, Wojciech Braksator ${ }^{1}$
}

Enlargement of the left atrium is perceived as a part of athlete's heart syndrome, despite the lack of evidence. So far, left atrial size has not been assessed in the context of exercise capacity. The hypothesis of the present study was that LA enlargement in athletes was physiological and fitness-related condition. In addition, we tried to assess the feasibility and normal values of left atrial strain parameters and their relationship with other signs of athlete's heart. The study group consisted of 114 international-level rowers $(17.5 \pm 1.5$ years old; $46.5 \%$ women). All participants underwent a cardio-pulmonary exercise test and resting transthoracic echocardiography. Beside standard echocardiographic measurements, two dimensional speckle tracking echocardiography was used to assess average peak atrial longitudinal strain, peak atrial contraction strain and early left atrial diastolic longitudinal strain. Mild, moderate and severe left atrial enlargement was present in $27.2 \%, 11.4 \%$ and $4.4 \%$ athletes, respectively. There were no significant differences between subgroups with different range of left atrial enlargement in any of echocardiographic parameters of the left ventricle diastolic function, filling pressure or hypertrophy. A significant correlation was found between the left atrial volume index and maximal aerobic capacity $(R>0.3 ; p<0.001)$. Left atrial strain parameters were independent of atrial size, left ventricle hypertrophy and left ventricle filling pressure. Decreased peak atrial longitudinal strain was observed in 4 individuals (3.5\%). We concluded that LA enlargement was common in healthy, young athletes participating in endurance sport disciplines with a high level of static exertion and was strictly correlated with exercise capacity, therefore, could be perceived as another sign of athlete's heart.

Key words: speckle tracking echocardiography, left atrium, maximal aerobic capacity, strain.

\section{Introduction}

Athlete's heart as a result of intensive, prolonged exercise has been investigated for many years. It has been suggested that training, especially in endurance sports, can lead to both left and right atrial enlargement (D'Andrea et al., 2010; Pagourelias et al., 2013; Pelliccia et al., 2005). Many previous studies have proved that left ventricular remodeling due to physical activity is physiological as the diastolic and systolic function remains normal or even supernormal. Left atrium (LA) enlargement is perceived as physiological as well by extrapolation, even though data confirming this statement is lacking. LA is of particular interest owing to its involvement in

1 - Medical University of Warsaw, Poland 2nd Medical Faculty, Department of Cardiology, Hypertension and Internal Medicine.

2- Institute of Sport, Warsaw, Poland.

3 - Infrastructure and Management College in Warsaw, Faculty of Health Sciences.

4- Medical University of Warsaw, Poland 2nd Medical Faculty, 3rd Department of Internal Medicine and Cardiology. 
pathophysiology of atrial fibrillation (AF) which is arrhythmia more often occurring in athletes then in sedentary controls (Baldesberger et al., 2008).

Deformation (strain and strain rate) analysis, assessed with two-dimensional speckle tracking echocardiography (2D STE), is a new echocardiographic method that allows a noninvasive evaluation of the atrial function. Decreased LA strain and the strain rate enable to predict the onset of atrial fibrillation (Cameli et al., 2014; Shaikh et al., 2012; Spethmann et al., 2014; Yoon et al., 2012). Moreover, strain value correlates with atrial fibrosis in paroxysmal and persistent AF (Kuppahally et al., 2010). Left atrial deformation assessment has been previously carried out in male and female athletes (D'Andrea et al., 2008; D'Ascenzi et al., 2014, 2015; Sun et al., 2009). However, to our knowledge, there is no study that has determined normal values of LA strain in a large sample of elite athletes.

Even though increased exercise capacity is one of the most obvious results of intensive training, cardiopulmonary exercise test results were seldom correlated with echocardiography in the athletic population (Yamazaki et al., 2000). It is known that exercise capacity is correlated with left ventricle size (Whyte et al., 2000; Yamazaki et al., 2000). Whether LA size also correlates with fitness has not been studied before.

Among all sports, those which combine high static and dynamic exertion induce the morphologic adaptation of the heart to the highest degree. Therefore, the biggest LA enlargement can be expected in those groups of athletes (Pelliccia et al., 2005).

The hypothesis of the study was that LA enlargement in athletes was physiologic, fitnessrelated condition in both male and female athletes. In addition, we tried to assess the feasibility of left atrial strain parameters and their relation with other signs of athletes' heart observed in echocardiography. Last of all, we aimed to establish the normal values of 2D STE left atrial strain in young, healthy athletes.

\section{Material and Methods}

The study group was comprised of 117 young, elite international-level rowers, average age of 17.5 years (15-21), participating in a routine annual medical check-up in the Institute of Sport (Warsaw, Poland) between January and March,
2013. The study was conducted during the preseason preparation period, in the middle of the intensive training program. The medical assessment was performed in the morning (at least 12 hours from the last training session) and consisted of consecutive stages: clinical and physical examination, resting ECG, transthoracic echocardiography and an exercise cardiopulmonary test. The incremental exercise test $(3 \mathrm{~min}$ exercise bouts interspersed with $30 \mathrm{~s}$ rest) until exhaustion was performed on a Concept-II ergonometer (Morrisville, USA). The respiratory exchange parameters were measured with the MetaLyser 3B and MetaMax 3B system (Cortex, Germany). The exact methodology of the cardiopulmonary test had been previously described (Klusiewicz et al., 2014). Maximal aerobic capacity (VO2max) was expressed in $1 / \mathrm{min}$ and in $\mathrm{ml} / \mathrm{kg} / \mathrm{min}$. Exclusion criteria were hypertension, valvular heart disease, cardiomyopathy, absence of sinus rhythm, pulmonary disease, endocrine disease and/or renal failure. For final analysis, only participants with acceptable quality of echocardiographic examination were included. All athletes gave informed consent. The Research Ethics Committee of the Institute of Sport (Warsaw, Poland) approved of the study protocol.

Echocardiographic examination was performed by two experienced physicians, using a Vivid 7 machine (GE, Vingmed Ultrasound, Boston, USA), with a M4S 1.5 to $4.0 \mathrm{MHz}$ transducer. ECG was continuously registered. Attention was given to adjust the ECG curve (lead selection, gain control) in order to present a well defined $\mathrm{P}$ wave and QRS complex. The examination was performed at rest in the leftlateral decubitus position using standard parasternal and apical views. All echocardiographic acquisitions were digitally stored and off-line analysis from three consecutive cardiac cycles was performed using dedicated software (EchoPac ver. 112 GE, USA). The chamber size measurements were performed according to recommendations (Lang et al., 2015; Rudski et al., 2010). In order to decrease the influence of preload-dependent parameters and to increase the quality of recorded data, all acquisitions were made during shallow endexpiration. Body surface area (BSA) was calculated according to the Mosteller's formula 
(1987).

LA measurements were performed at left ventricular end-systole, in atrial maximal size. The LA area was measured in a 4-chamber view. LA volume (LAV) was calculated by the Simpson's method and then indexed to the body surface area as a LA volume index (LAVI). During LA size assessment the LA appendage and pulmonary veins were excluded and mitral valve annulus plane was used as the inferior border. LA enlargement was defined as follows (Lang et al., 2015): Mild $\geq 34 \mathrm{ml} / \mathrm{m} 2$ and $<42 \mathrm{ml} / \mathrm{m} 2$, moderate $\geq$ $42 \mathrm{ml} / \mathrm{m} 2$ and $<48 \mathrm{ml} / \mathrm{m} 2$, severe $>48 \mathrm{ml} / \mathrm{m} 2$.

STE derived LA strain analysis was performed offline by one physician. The methodology was adopted to comply with methodology used in the most experienced echo-labs involved in athletes' assessment which showed good reproducibility (D'Ascenzi et al., 2012). The ultrasound focus position was set on the level of LA to optimize the image quality, the frame rate was set between 60$80 \mathrm{~Hz}$. The commercially available 2D semiautomated software was used (Echo Pac, ver. 112). The strain measurement was performed on generated curves. The scale was adjusted to set 0 level at the beginning of the QRS complex. The average (from all accepted segments) peak atrial longitudinal strain (PALS) and peak atrial contraction strain (PACS) were measured, as parameters of atrial reservoir and atrial pump (buster), respectively. The difference between PALS and PACS was early LA diastolic longitudinal strain (ELAS) and represented passive conduit function. PACS was defined as maximal longitudinal strain before the peak of the P wave (Figure 1).

To distinguish athletes with low PALS, normal values of PALS for the general healthy population were used from the study of Cameli et al. (2009) using the same methodology, echo system and software vendor.

\section{Statistical analysis}

For statistical analysis, commercially available software STATISTICA ver. 10 (StatSoft, Tulsa, USA) was used. Continuous variables are presented as mean \pm standard deviation (SD), categorical variables as percentages. Normal distribution of all continuous variables was examined using the Shapiro-Wilk test. The unpaired t-test and the Mann-Whitney u-test were used according to data distribution to assess between-groups differences in continuous variables and chi-square for categorical variables. The correlations between continuous variables were assessed with the Pearson correlation coefficient ( $r$ ) and between categorical variables with the Spearman rank correlation coefficient, correlations with $\mathrm{R}>0.3$ with $\mathrm{p}<0.05$ were reported. In order to assess significance of differences between multiple subgroups analysis of variance (ANOVA) was used. The post hoc Scheffe test was performed to distinguish the intergroup differences. The level of significance was set at $p<$ 0.05 .

\section{Results}

\section{Clinical characteristics and conventional echocardiography}

General characteristics of the examined group are presented in Table 1. From primarily examined 117 athletes, 114 were finally included in the analysis. All exclusions were due to poor image quality. No cardiovascular disorder was found. From the analyzed 114 athletes 53 were female $(46.5 \%)$. Standard echocardiographic and Doppler parameters are summarized in Table 2. The parameters of LA size are presented in Table 3. Left atrium enlargement according to LAVI was present in nearly half of the athletes (43\%) and was more frequent in man then in women $(52.5 \%$ vs $32.1 \%$; $\mathrm{p}<0.05$ ). Mild, moderate or severe LA enlargement was present in $27.2 \%, 11.4 \%$ and $4.4 \%$ athletes, respectively. Following ANOVA results, there were no significant differences between subgroups with different ranges of LA enlargement with regard to left ventricular parameters of the diastolic function (mitral $\mathrm{E}$ and A waves velocities, E/A ratio), filling pressure (E/e') and hypertrophy (LVMI, IVSd).

\section{Cardiopulmonary exercise test}

Cardiopulmonary exercise test parameters are presented in Table 3. Maximal aerobic capacity was, as expected, higher in males, both in absolute $(1 / \mathrm{min})$ and relative $(\mathrm{ml} / \mathrm{min} / \mathrm{kg})$ values. Resting and maximal exercise heart rates were similar in males and females. VO2max correlated significantly with most LA size parameters (except LA area indexed to BSA).

Left atrial strain analysis

From the primary group of 117 athletes, 114 (97\%) had acceptable image quality for STE analysis. From this group the assessment of $97.7 \%$ 
of LA segments (668/684) was feasible. In 10 athletes (9\%) one segment and in 3 athletes (2.6\%) two segments could not be traced properly. The LA roof and interatrial septum were the regions of poor tracking quality in 6 athletes and 5 athletes, respectively (see technical consideration). STE derived LA strain parameters are presented in Table 4 with 5-95 percentile as suggested by normal ranges. Linear correlation between LA strain and parameters of: diastolic function (mitral inflow E velocity, E deceleration time, A velocity, E/A ratio, TDI mitral velocities: $\left.E^{\prime}, A^{\prime}, E / E^{\prime}\right), L V$ size and hypertrophy (LVM, LVMI, LVEDd, IVSd), exercise capacity (VO2max) and LA size
(LAV, LAVI, LA area, LA diameter) were assessed. No significant correlation was found between LA functional parameters and LV and LA morphology. No significant correlation was noted between LA strain and parameters of exercise capacity. According to normal value for general population, decreased LA PALS $(<29 \%)$ was present in 4 athletes $(3.5 \%)$. The only significant differences in athletes with reduced PALS were a larger intraventricular septum diameter $(1.15 \mathrm{vs} 1.07 \mathrm{~cm})$, a lower mitral $\mathrm{E}$ wave velocity $(78 \mathrm{~cm} / \mathrm{s}$ vs $98 \mathrm{~cm} / \mathrm{s})$ and consequently higher mitral E/E' (6.0 vs 5.0).

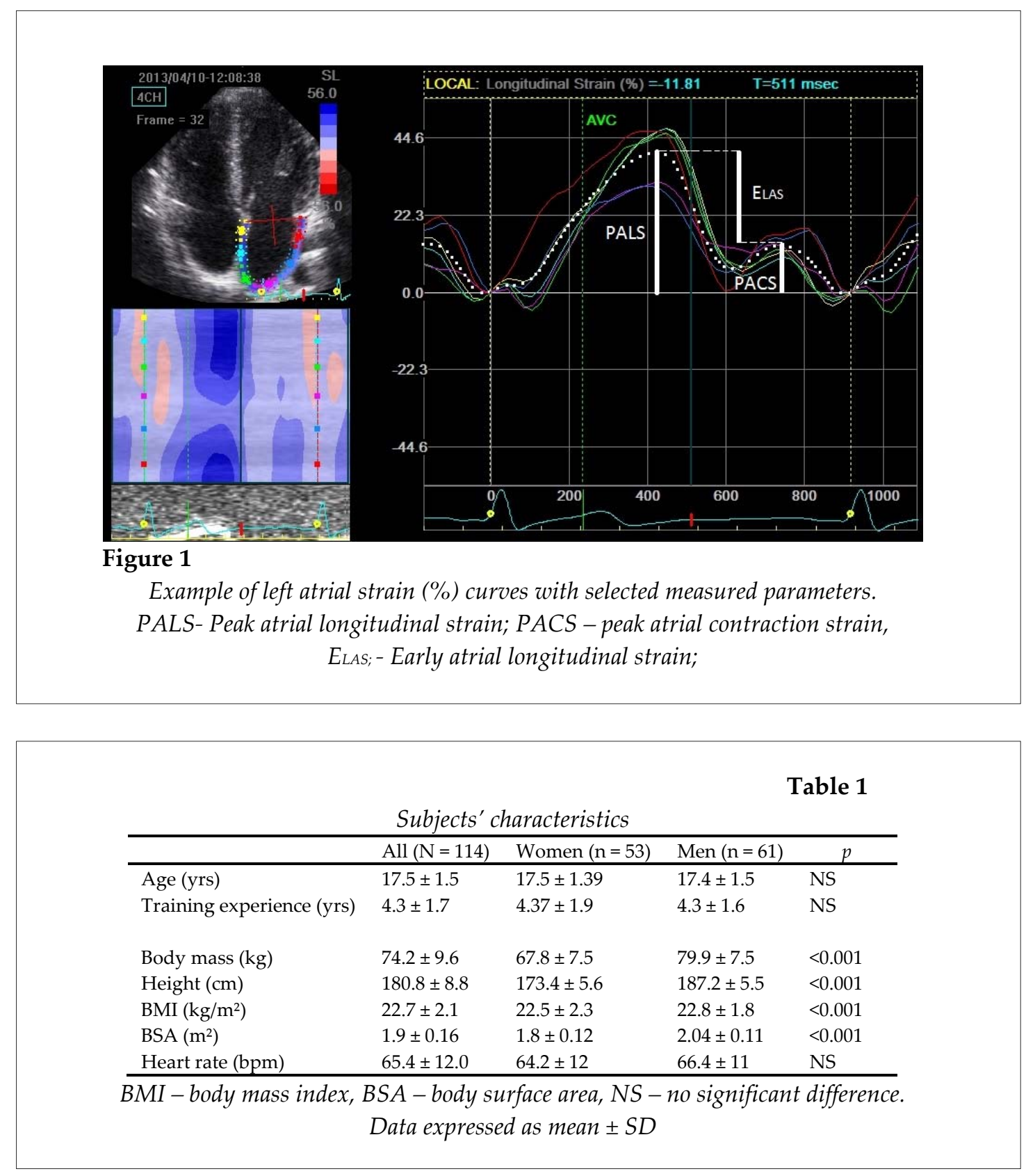




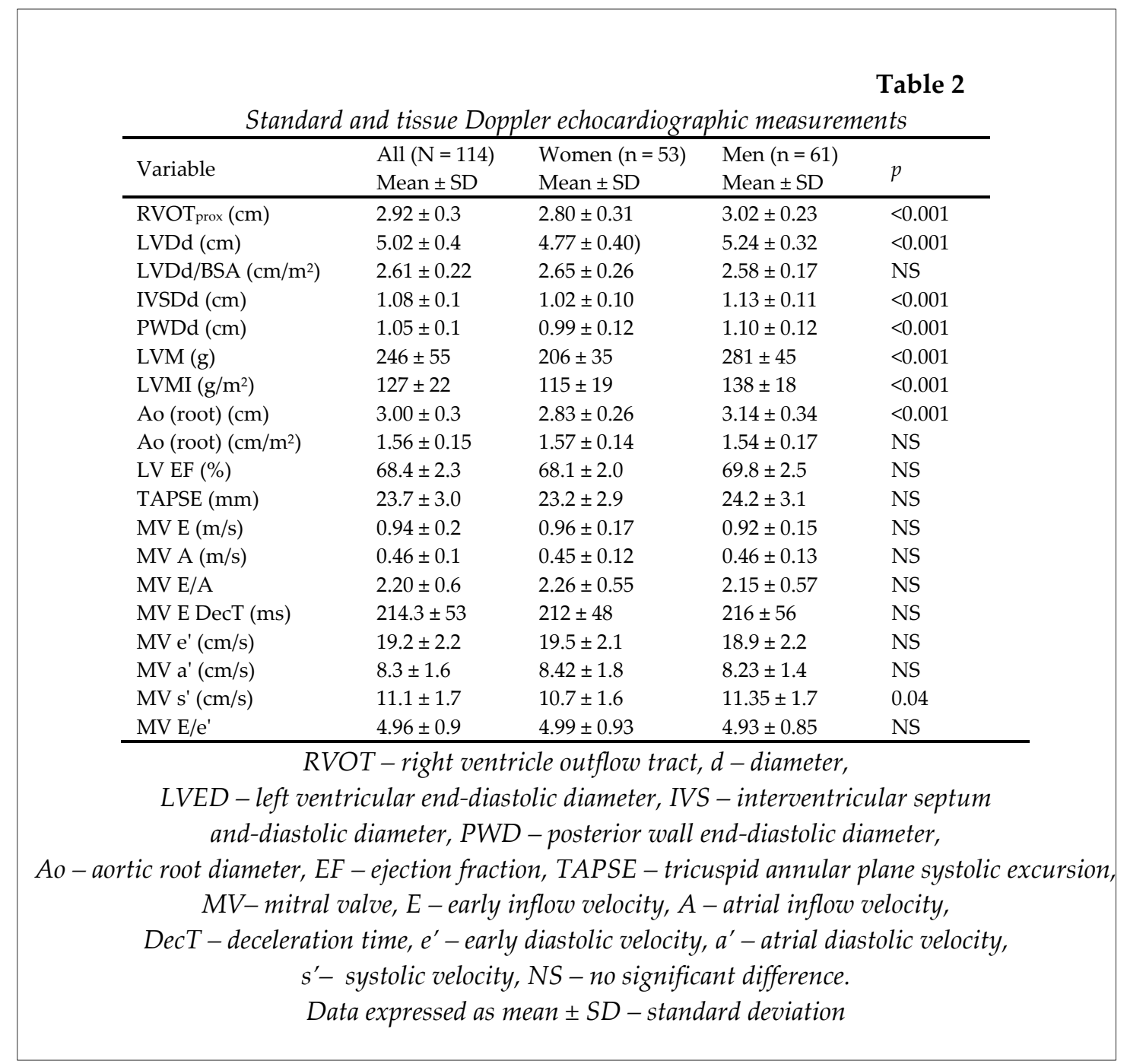

Table 3

Atrial size parameters and cardiopulmonary test results in the examined group of rowers

\begin{tabular}{|c|c|c|c|c|}
\hline & $\begin{array}{l}\text { All }(\mathrm{N}=114) \\
\text { Mean } \pm S D\end{array}$ & $\begin{array}{l}\text { Women }(\mathrm{n}=53) \\
\text { Mean } \pm \text { SD }\end{array}$ & $\begin{array}{l}\text { Men }(n=61) \\
\text { Mean } \pm \text { SD }\end{array}$ & $p$ \\
\hline $\mathrm{LA}(\mathrm{cm})$ & $3.65 \pm 0.40$ & $3.50 \pm 0.3$ & $3.77 \pm 0.44$ & $<0.001$ \\
\hline LAA $\left(\mathrm{cm}^{2}\right)$ & $22.6 \pm 3.4$ & $20.1 \pm 2.6$ & $24.0 \pm 3.4$ & $<0.001$ \\
\hline RAA $\left(\mathrm{cm}^{2}\right)$ & $18.0 \pm 3.1$ & $16.6 \pm 2.7$ & $19.3 \pm 2.8$ & $<0.001$ \\
\hline $\mathrm{LA} / \mathrm{BSA}\left(\mathrm{cm} / \mathrm{m}^{2}\right)$ & $1.90 \pm 0.20$ & $1.95 \pm 0.17$ & $1.86 \pm 0.22$ & 0.02 \\
\hline RAA/BSA $\left(\mathrm{cm}^{2} / \mathrm{m}^{2}\right)$ & $9.35 \pm 1.4$ & $9.20 \pm 1.53$ & $9.48 \pm 1.27$ & NS \\
\hline LAA/BSA $\left(\mathrm{cm}^{2} / \mathrm{m}^{2}\right)$ & $11.7 \pm 1.6$ & $11.7 \pm 1.5$ & $11.8 \pm 1.6$ & NS \\
\hline $\operatorname{LAV}\left(\mathrm{cm}^{3}\right)$ & $66.3 \pm 15.3$ & $57.5 \pm 11$ & $73.9 \pm 14.5$ & $<0.001$ \\
\hline LAVI $\left(\mathrm{cm}^{3} / \mathrm{m}^{2}\right)$ & $34.3 \pm 6.9$ & $31.9 \pm 6.1$ & $36.3 \pm 6.9$ & $<0.001$ \\
\hline $\mathrm{VO}_{2 \max }(1 / \mathrm{min})$ & $4.20 \pm 0.9$ & $3.36 \pm 0.4$ & $4.94 \pm 0.6$ & $<0,001$ \\
\hline $\mathrm{VO}_{2 \max }(\mathrm{ml} / \mathrm{kg} / \mathrm{min})$ & $56.4 \pm 8.2$ & $49.9 \pm 5.1$ & $62,1 \pm 5.8$ & $<0,001$ \\
\hline $\mathrm{HR}_{\max }(/ \min )$ & $195 \pm 8.2$ & $194 \pm 7.6$ & $195 \pm 8.7$ & NS \\
\hline
\end{tabular}

$L A$ - left atrial diameter, $L A A$ - left atrial area, $R A A$ - right atrial area,

$B S A$ - body surface area, LAV - left atrial volume, LAVI - left atrial volume index,

$V O_{2 \max }$ - maximal aerobic capacity, HRmax - maximal heart rate.

Data expressed as mean $\pm S D$ - standard deviation 


\section{Table 4}

Mean values of two dimensional speckle tracking echocardiography left atrial strain parameters assessed in 4-chamber view, with 5-95 percentile as normal value.

\begin{tabular}{lccccc}
\hline & $\begin{array}{c}\text { All }(\mathrm{N}=114) \\
\text { Mean } \pm \text { SD }\end{array}$ & $\begin{array}{c}5-95 \\
\text { Percentile }\end{array}$ & $\begin{array}{c}\text { Women }(\mathrm{n}=53) \\
\text { Mean } \pm \text { SD }\end{array}$ & $\begin{array}{c}\text { Men }(\mathrm{n}=61) \\
\text { Mean } \pm \text { SD }\end{array}$ & $\begin{array}{c}p \\
\text { (Men vs Women) }\end{array}$ \\
\hline PALS (\%) & $42.3( \pm 8.1)$ & $30.0-58.1$ & $42.9 \pm 0.1$ & $41.7 \pm 0.1$ & NS \\
$\begin{array}{l}\text { PACS } \\
(\%)\end{array}$ & $12.1( \pm 3.6)$ & $6.75-19.0$ & $12.2 \pm 3.6$ & $12.1 \pm 3.7$ & NS \\
ELAS (\%) & $30.2( \pm 7.2)$ & $20.6-44.4$ & $30.7 \pm 7.4$ & $29.7 \pm 7.0$ & NS \\
\hline
\end{tabular}

PALS - Peak atrial longitudinal strain, PACS - peak atrial contraction strain, ELAS, - Early atrial longitudinal strain, TPALS - time to peak atrial strain,

$T P A C S$ - time to peak atrial contraction strain, RR - time between consecutive heart cycles. Data expressed as mean $\pm S D-$ standard deviation

\section{Correlation between $\mathrm{VO}_{2 \max }$ and $\operatorname{LAV}(r=0,35 ; p<0,001)$}

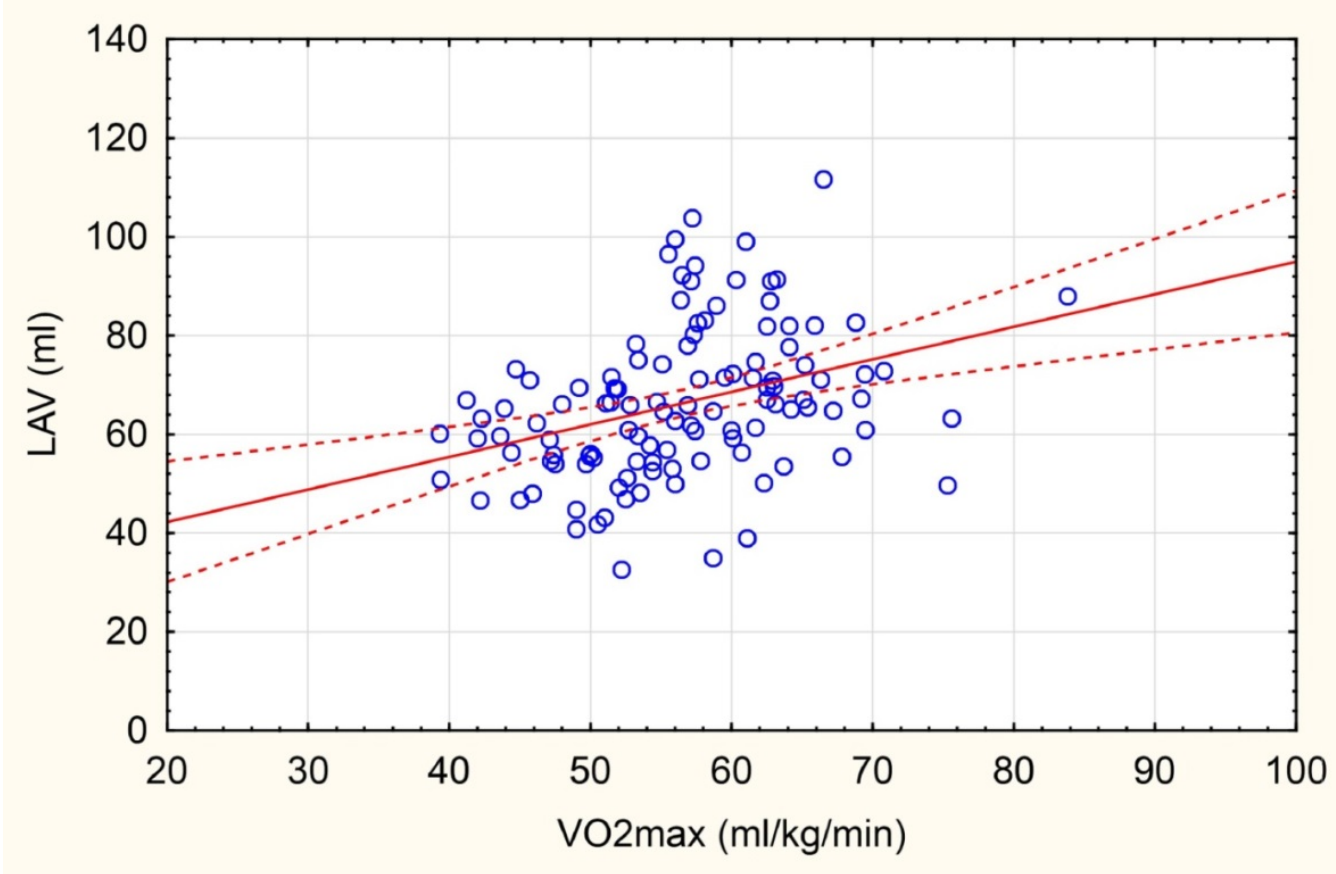

Figure 2

Correlation between left atrial volume and maximal aerobic capacity. $L A V$ - left atrial volume, $V O_{2 m a x}$ - maximal aerobic capacity 


\section{Discussion}

In our study we demonstrated that left atrial enlargement was common condition in young, healthy rowers. LA dilatation was more often observed in males, and was not related with LV hypertrophy or LV diastolic function what confirmed observations of D'Andrea et al. (2010). The most often postulated mechanism of physiological LA dilatation in athletes is due to an increased volume load in contrast to increased LV filling pressure observed in pathologic LV hypertrophy (Pelliccia et al., 2005). In our study, even though the selected group of athletes participated in one of the most demanding endurance sports, the degree of left atrial enlargement was surprisingly high, especially given the young age of participants. Observed LA volumes were comparable to those reported by Baggish et al. (2010) in senior, elite and sub-elite rowers. Despite the fact that in the updated Recommendation for Chamber Quantification published by Lang et al. (2015) the upper reference value of the LA volume index was increased, still more than $40 \%$ of young, healthy athletes exceeded the norms. This observation shows the need for establishing normal values of LAVI for this specific population what has been already postulated by other authors (Galderisi et al., 2015).

Left and right ventricle size is generally larger in male athletes, however, indexation with a body surface area can decrease observed differences (Konopka et al., 2015; Krol et al., 2011). A similar observation can be made with regard to LA enlargement in our examined group. In absolute numbers all LA size parameters (dimension, area and estimated volume) were significantly greater in males (Table 3). After indexation with the body surface area, differences of some measurements (atrial area) lose significance, but the most recommended parameter (LAVI) does not. The between gender differences in LAVI have been reported by other authors and discussed in the context of a lower incidence of AF in women (D'Andrea et al., 2010; Mont et al., 2009).

The relationship between results of cardiopulmonary tests and heart morphology in athletes has not been extensively studied. It was shown that $\mathrm{VO}_{2 \max }$ correlated with the $\mathrm{LV}$ diameter in athletes, but not in obese controls
(Yamazaki et al., 2000). Also the LV diameter and LV posterior wall thickness correlated positively with cycling performance in thriathletes (Mondillo et al., 2011). To our knowledge, this study is the first to show a similar relationship of left atrial size with exercise capacity. This observation gives another evidence of physiological nature of LA enlargement due to intensive training.

The image quality which is a main limitation of 2D STE is very important in reliable quantitative strain assessment. Athletes, having in general a very good acoustic window, seem to be an appropriate population for the wider introduction of STE into clinical practice. In our study, the functional assessment of LA was feasible in nearly all examined athletes. The important information is that LA STE derived strain was independent of LA size, which had been postulated before based on smaller sample groups ( $\mathrm{N}<25)$ (D'Ascenzi et al., 2012; Gabrielli et al., 2014). LA systolic and diastolic strains in young athletes are also independent of the parameters of left ventricular hypertrophy and left ventricle filling pressure. In this regard, LA strain analysis can be used in differentiating pathological and physiological left ventricular hypertrophy in hypertrophic cardiomiopathy and in hypertension what has been investigated before (D'Andrea et al., 2008; Sun et al., 2009).

Although LA enlargement is common condition in athletes, only few data exist on the long term clinical consequences of this phenomenon. It has been shown that LA enlargement is more prominent in athletes with electrocardiographic changes such as early repolarisation (Konopka et al., 2016). There are theories suggesting that LA enlargement and remodeling may contribute to paroxysmal supraventricular arrhythmias in athletes (Benito et al., 2011; Guasch et al., 2013). Benito et al. (2011) on an animal mice model found that intensive, prolonged physical training led to increased LA dilatation and fibrosis accompanied with increased arrhythmia inducibility. Nevertheless, some studies have shown that despite high prevalence of LA dilatation in athletes participating in IIIC sports, AF develops in a small percentage of them (Pelliccia et al., 2005). Even though LA dilatation may be present in more than $3 / 4$ of endurance athletes, the highest 
prevalence of AF reported by Baldesberger et al. (2008) was "only" $10 \%$ in the $7^{\text {th }}$ decade of life (Baldesberger et al., 2008). These data suggest that LA enlargement alone is not a good indicator of the risk for AF. Therefore, other predictors of AF should be sought. Functional atrial assessment seems to be one of possibilities.

In our study, we applied the most often cited methodology from the center experienced in sports cardiology (D'Ascenzi et al., 2012, 2014, 2015). In this setting, LA strain parameters assessed in 2D STE were very similar to other publications evaluating different groups of athletes, which strengthens the reproducibility of the method. The significance of the observed decreased $(<29 \%)$ PALS in 4 athletes $(3.5 \%)$, described as a normal for the general population by Camelli et al. (2009), needs further observation. So far the medical follow-up has not revealed any pathologies.

In summary, our study provides new information about LA morphologic and functional remodeling in athletes, which confirms that LA enlargement may be legitimately perceived as another sign of athlete's heart.

\section{Conclusions:}

1. LA enlargement is common in healthy, young athletes participating in endurance sport disciplines with a high level of static exertion and is strictly correlated with exercise capacity, therefore, can be perceived as another sign of athlete's heart.

2. In endurance athletes with LA enlargement, there are no echocardiographic signs of an impaired LV diastolic function or increased LV filling pressure.

3. The magnitude of left atrial strains assessed in STE is not correlated with LA enlargement, LV hypertrophy or LV diastolic function in the population of healthy, young competitive athletes.

\section{References}

Baggish AL, Yared K, Weiner RB, Wang F, Demes R, Picard MH, Hagerman F, Wood MJ. Differences in cardiac parameters among elite rowers and subelite rowers. Med Sci Sports Exerc, 2010; 42: 1215-1220

Baldesberger S, Bauersfeld U, Candinas R, Seifert B, Zuber M, Ritter M, Jenni R, Oechslin E, Luthi P, Scharf C, Marti B, Attenhofer Jost $\mathrm{CH}$. Sinus node disease and arrhythmias in the long-term follow-up of former professional cyclists. Eur Heart J, 2008; 29: 71-78

Benito B, Gay-Jordi G, Serrano-Mollar A, Guasch E, Shi Y, Tardif JC, Brugada J, Nattel S, Mont L. Cardiac arrhythmogenic remodeling in a rat model of long-term intensive exercise training. Circulation, 2011; 123: $13-22$

Cameli M, Caputo M, Mondillo S, Ballo P, Palmerini E, Lisi M, Marino E, Galderisi M. Feasibility and reference values of left atrial longitudinal strain imaging by two-dimensional speckle tracking. Cardiovasc Ultrasound, 2009; 7: 6

Cameli M, Lisi M, Reccia R, Bennati E, Malandrino A, Solari M, Bigio E, Biagioli B, Righini FM, Maccherini M, Chiavarelli M, Henein M, Mondillo S. Pre-operative left atrial strain predicts post-operative atrial fibrillation in patients undergoing aortic valve replacement for aortic stenosis. Int J Cardiovasc Imaging, 2014; 30: 279-286

D'Andrea A, De Corato G, Scarafile R, Romano S, Reigler L, Mita C, Allocca F, Limongelli G, Gigantino G, Liccardo B, Cuomo S, Tagliamonte G, Caso P,Calbro R. Left atrial myocardial function in either physiological or pathological left ventricular hypertrophy: a two-dimensional speckle strain study. $\mathrm{Br}$ J Sports Med, 2008; 42: 696-702

D'Andrea A, Riegler L, Cocchia R, Scarafile R, Salerno G, Gravino R, Golia E, Vriz O, Citro R, Limongelli G, Calabro P, Di Salvo G, Caso P, Russo MG, Bossone E, Calabro R. Left atrial volume index in highly trained athletes. Am Heart J, 2010; 159: 1155-1161

D'Ascenzi F, Cameli M, Lisi M, Zaca V, Natali B, Malandrino A, Benincasa S, Catanese S, Causarano A, Mondillo S. Left atrial remodelling in competitive adolescent soccer players. Int J Sports Med, 2012; 33: 795-801 
D'Ascenzi F, Pelliccia A, Natali BM, Cameli M, Andrei V, Incampo E, Alvino F, Lisi M, Padeletti M, Focardi M, Bonifazi M, Mondillo S. Increased left atrial size is associated with reduced atrial stiffness and preserved reservoir function in athlete's heart. Int J Cardiovasc Imaging, 2015; 31: 699-705

D'Ascenzi F, Pelliccia A, Natali BM, Zaca V, Cameli M, Alvino F, Malandrino A, Palmitesta P, Zorzi A, Corrado D, Bonifazi M, Mondillo S. Morphological and functional adaptation of left and right atria induced by training in highly trained female athletes. Circ Cardiovasc Imaging, 2014; 7: 222-229

Gabrielli L, Bijnens BH, Butakoff C, Duchateau N, Montserrat S, Merino B, Gutierrez J, Pare C, Mont L, Brugada J, Sitges M. Atrial functional and geometrical remodeling in highly trained male athletes: for better or worse? Eur J Appl Physiol, 2014; 114: 1143-1152

Galderisi M, Cardim N, D'Andrea A, Bruder O, Cosyns B, Davin L, Donal E, Edvardsen T, Freitas A, Habib G, Kitsiou A, Plein S, Petersen SE, Popescu BA, Schroeder S, Burgstahler C, Lancellotti P. The multimodality cardiac imaging approach to the Athlete's heart: an expert consensus of the European Association of Cardiovascular Imaging. Eur Heart J Cardiovasc Imaging, 2015; 16: 353

Guasch E, Benito B, Qi X, Cifelli C, Naud P, Shi Y, Mighiu A, Tardif JC, Tadevosyan A, Chen Y, Gillis MA, Iwasaki YK, Dobrev D, Mont L, Heximer S, Nattel S. Atrial fibrillation promotion by endurance exercise: demonstration and mechanistic exploration in an animal model. J Am Coll Cardiol, 2013; 62: 68-77

Klusiewicz A, Starczewski M, Ladyga M, Dlugolecka B, Braksator W, Mamcarz A, Sitkowski D. Reference values of maximal oxygen uptake for Polish rowers. J Hum Kinet, 2014; 44: 121-127

Konopka M, Banach M, Burkhard-Jagodzińska K, Król W, Anioł K, Sitkowski D, Pokrywka A, Klusiewicz A, Ładyga M, Orysiak J, Dłużniewski M, Braksator W. Echocardiographic evaluation of cardiovascular system in adolescent athletes in view of physiological adaptation to physical training. Folia Cardiologica, 2015a; 10: 233-241

Konopka M, Burkhard-Jagodzinska K, Aniol-Strzyzewska K, Krol W, Klusiewicz A, Chwalbinska J, Pokrywka A, Sitkowski D, Dluzniewski M, Braksator W. The prevalence and determinants of early repolarization pattern in the group of young high endurance athletes - rowers. Kardiol Pol, 2016; 74: 289-299

Krol W, Braksator W, Kasprzak JD, Kuch M, Mamcarz A, Chybowska B, Krysztofiak H, Dluzniewski M. The influence of extreme mixed exertion load on the right ventricular dimensions and function in elite athletes: a tissue Doppler study. Echocardiography, 2011; 28: 753-760

Kuppahally SS, Akoum N, Burgon NS, Badger TJ, Kholmovski EG, Vijayakumar S, Rao SN, Blauer J, Fish EN, Dibella EV, Macleod RS, McGann C, Litwin SE, Marrouche NF. Left atrial strain and strain rate in patients with paroxysmal and persistent atrial fibrillation: relationship to left atrial structural remodeling detected by delayed-enhancement MRI. Circ Cardiovasc Imaging, 2010; 3: 231-239

Lang RM, Badano LP, Mor-Avi V, Afilalo J, Armstrong A, Ernande L, Flachskampf FA, Foster E, Goldstein SA, Kuznetsova T, Lancellotti P, Muraru D, Picard MH, Rietzschel ER, Rudski L, Spencer KT, Tsang W, Voigt JU. Recommendations for cardiac chamber quantification by echocardiography in adults: an update from the American Society of Echocardiography and the European Association of Cardiovascular Imaging. Eur Heart J Cardiovasc Imaging, 2015; 16: 233-270

Mondillo S, Cameli M, Caputo ML, Lisi M, Palmerini E, Padeletti M, Ballo P. Early detection of left atrial strain abnormalities by speckle-tracking in hypertensive and diabetic patients with normal left atrial size. J Am Soc Echocardiogr, 2011; 24: 898-908

Mont L, Elosua R, Brugada J. Endurance sport practice as a risk factor for atrial fibrillation and atrial flutter. Europace, 2009; 11: 11-17

Mosteller RD. Simplified calculation of body-surface area. N Engl J Med, 1987; 317: 1098

Pagourelias ED, Kouidi E, Efthimiadis GK, Deligiannis A, Geleris P, Vassilikos V. Right atrial and ventricular adaptations to training in male Caucasian athletes: an echocardiographic study. J Am Soc Echocardiogr, 2013; 26: 1344-1352

Pelliccia A, Maron BJ, Di Paolo FM, Biffi A, Quattrini FM, Pisicchio C, Roselli A, Caselli S, Culasso F. 
Prevalence and clinical significance of left atrial remodeling in competitive athletes. J Am Coll Cardiol, 2005; 46: 690-696

Rudski LG, Lai WW, Afilalo J, Hua L, Handschumacher MD, Chandrasekaran K, Solomon SD, Louie EK, Schiller NB. Guidelines for the echocardiographic assessment of the right heart in adults: a report from the American Society of Echocardiography endorsed by the European Association of Echocardiography, a registered branch of the European Society of Cardiology, and the Canadian Society of Echocardiography. J Am Soc Echocardiogr, 2010; 23: 685-713; quiz 786-688

Shaikh AY, Maan A, Khan UA, Aurigemma GP, Hill JC, Kane JL, Tighe DA, Mick E, McManus DD. Speckle echocardiographic left atrial strain and stiffness index as predictors of maintenance of sinus rhythm after cardioversion for atrial fibrillation: a prospective study. Cardiovasc Ultrasound, 2012; 10: 48

Spethmann S, Stuer K, Diaz I, Althoff T, Hewing B, Baumann G, Dreger H, Knebel F. Left atrial mechanics predict the success of pulmonary vein isolation in patients with atrial fibrillation. J Interv Card Electrophysiol, 2014; 40: 53-62

Sun P, Wang ZB, Li JX, Nie J, Li Y, He XQ, Su XT. Evaluation of left atrial function in physiological and pathological left ventricular myocardial hypertrophy by real-time tri-plane strain rate imaging. Clin Cardiol, 2009; 32: 676-683

Whyte G, Lumley S, George K, Gates P, Sharma S, Prasad K, McKenna WJ. Physiological profile and predictors of cycling performance in ultra-endurance triathletes. J Sports Med Phys Fitness, 2000; 40: 103-109

Yamazaki H, Onishi S, Katsukawa F, Ishida H, Kinoshita N. Peak aerobic performance and left ventricular morphological characteristics in university students. Clin J Sport Med, 2000; 10: 286-290

Yoon YE, Kim HJ, Kim SA, Kim SH, Park JH, Park KH, Choi S, Kim MK, Kim HS, Cho GY. Left atrial mechanical function and stiffness in patients with paroxysmal atrial fibrillation. $J$ Cardiovasc Ultrasound, 2012; 20: 140-145

\section{Corresponding author:}

\section{Wojciech Król}

Department of Cardiology, Hypertension and Internal Medicine,

Medical University of Warsaw; Brodnowski Hospital

ul. Kondratowicza 8; 03-282 Warsaw, Poland

Phone: +48 601168992

Fax: +48 223265605

E-mail:wukrol@gmail.com 